Revista Brasileira de Farmacognosia Brazilian Journal of Pharmacognosy 21(5): 786-792, Sep./Oct. 2011

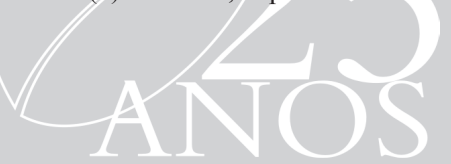

Article

Received 27 Dec 2010

Accepted 8 Mar 2011

Available online 24 Jun 2011

Keywords:

Apis

free-choice profile

honey

Huottuja

Meliponini

sensory analysis

ISSN 0102-695X

http://dx.doi.org/10.1590/S0102695X2011005000115

\section{How a Huottuja (Piaroa) community perceives genuine and false honey from the Venezuelan Amazon, by free-choice profile sensory method}

\author{
Patricia Vit, ${ }^{*,}$ Rosires Deliza, ${ }^{2,3}$ Alfonso Pérez ${ }^{4}$ \\ ${ }^{1}$ Departamento Ciencia de Los Alimentos, Facultad de Farmacia y Bioanálisis, \\ Universidad de Los Andes, Venezuela, \\ ${ }^{2}$ Embrapa Agroindústria de Alimentos, Brazil, \\ ${ }^{4}$ Asociación Cooperativa de Meliponicultores Warime, Venezuela.
}

\begin{abstract}
Pot honey is the most abundant honey in the forest, produced by many species of stingless bees (Meliponini) of the Huottuja (Piaroa) community in Paria Grande, Venezuela. However, the commercialization of this honey is low, and false honeys, which are sold in labelled bottles, are easily found in the market. This study has investigated the ability of an untrained panel of Piaroa assessors to differentiate the genuine from the false pot honey using the Free-choice profile. This sensory method allows consumers to use their own words to describe and to quantify sensory attributes of a product. The genuine honeys, light amber Melipona fuscopilosa "isabitto" and dark amber Tetragona clavipes "ajavitte", the false light and dark "angelita" honeys, and the amber Apis mellifera honey, were evaluated. Sensory attributes related to the appearance, color, odor, flavor and mouthfeel were elicited in a qualitative session and were quantified in 10-cm unstructured line scales using individual score sheets. The data were analyzed by Generalized Procrustes Analysis (GPA). The bidimensional plot successfully separated genuine from false pot honeys. The first dimension $(39.50 \%)$ was represented by the low viscosity, fermented odor and sour taste, whereas the second dimension $(24.69 \%)$ was related to fruity and honey odor and flavor. Huottuja assessors differentiated the five honey types in terms of the perceived sensory characteristics.
\end{abstract}

\section{Introduction}

Honey standards from Brazil (Ministério da Agricultura, 2000) and Venezuela (Covenin, 1984) were produced only for Apis mellifera, following the guidelines of international standards of the Codex Alimentarius Commission(1969, 1987, 2001). However, stingless bees also produce honey. They differ from $A$. mellifera at the subfamily level known as Meliponini (Michener, 2000). A proposal for quality standards for meliponine honey was presented few years ago (Vit et al., 2004; Souza et al., 2006) and was inserted for the first time in a honey standard by the Colombian regulations (Norma Técnica Colombiana, 2007). This honey is produced primarily by Melipona, Scaptotrigona and Tetragonisca (in America), Meliponula (in Africa), and Tetragonula (in Asia and Australia). There are around sixty genera of stingless bees (Rasmussen \& Cameron, 2010), with 391 Neotropical species groups (Camargo $\&$ Pedro, 2007), and more than 500 are estimated worldwide.
Huottujas are an ethnic group of Amerindians in Venezuela (Melnyk \& Bell, 1996) known as piaroas by the public. The Huottuja community in Paria Grande, located about $30 \mathrm{~km}$ to the South of the city Puerto Ayacucho, capital of the Amazonas State, has organized a cooperative of meliponiculture since 2005, and call its honey as "mayá". Instead of honey hunting, they keep and multiply feral colonies in rational hives. Both local horizontal layout, and vertical hives that facilitate colony division, after the Brazilian experience (Villas Bôas, 2008) are used (Figure 1). Different stingless bee species exploit resources according to their honey, pollen or propolis yields (Kerr, 1987). Native people know that and use stingless bee products accordingly. After harvesting the honey, the cerumen pots are used to handcraft ceremonial Huottuja masks, and souvenirs. Honey was previously pressed but now is extracted with a syringe.

Sensory attributes of honey stored in pots by Meliponini have been investigated by several authors in the past (Schwarz 1948; Gonnet et al., 1964). Kidder 

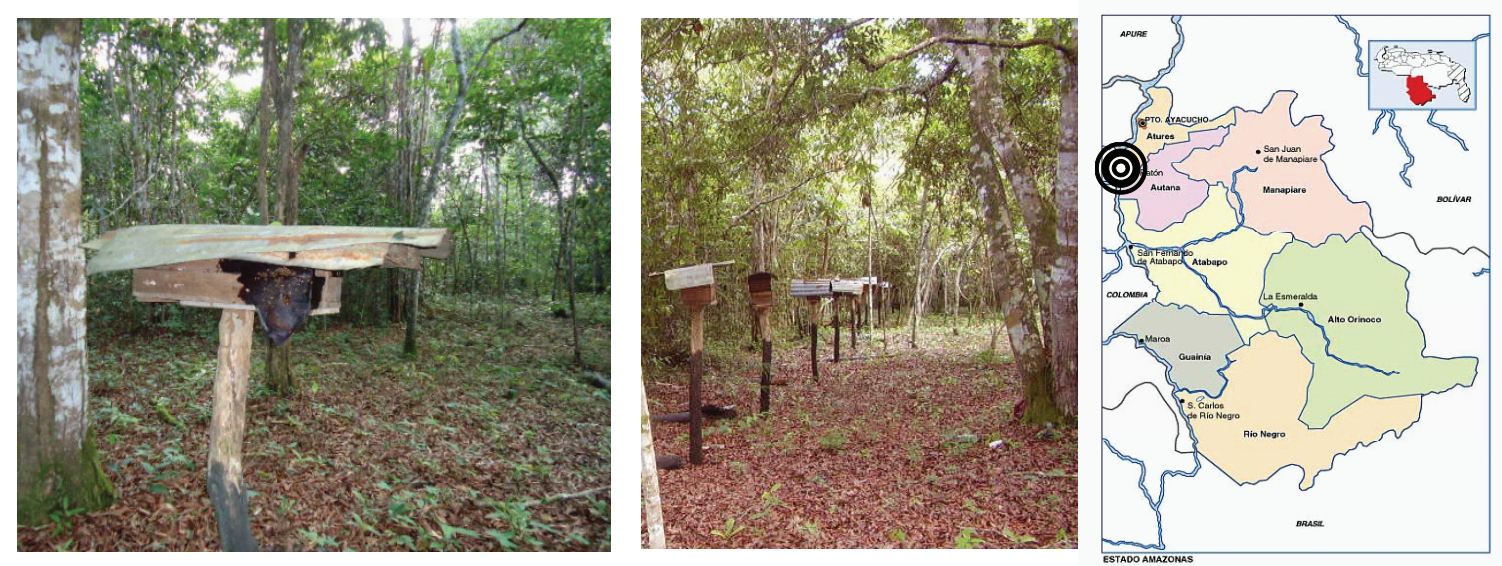

Figure 1. A meliponary from the Paria Grande, Amazonas State, Venezuela.

\& Fletcher (1857) suggested that the sour honey of Brazilian stingless bees "will compensate for sweet lemons". However, no study was carried out using any population from the Venezuelan Amazon to describe pot honey sensory attributes. This work aimed at investigating the genuine and false pot honeys from the Venezuelan Amazon as well as the comb honey by using the sensory Free-choice profiling (FCP) method by local people named Huottuja.

\section{Materials and Methods}

Honey

Two artificial honey samples (light and dark) were purchased at the local market in Puerto Ayacucho, Venezuela, named as "angelita", which is the common name given to Tetragonisca angustula honey. Salesmen informed that the light honey came from yellow flowers and the dark honey from purple flowers. Both honeys were bottled in a recycled glass container from a Colombian aguardiente distilled drink, and had a label. These honeys had the thick syrup visual appearance of artificial honeys. One of them had an ant inside, pretending to be a stingless bee. The insect inside the bottle is a local practice in false honey, also seen in the Venezuelan Andes. Two genuine meliponine honeys were provided by a local stingless beekeeper. These samples were already harvested and kept refrigerated. Entomological samples of these bees were kindly identified in the past at Universidade de São Paulo in Ribeirão Preto, Brazil. The five honey samples are described in Table 1.

The light amber honey was produced by "isabitto" Melipona fuscopilosa and the dark amber was produced by "ajavitte" Tetragona clavipes. The genuine and the false honeys are shown in Figure 2. Additionally, we used a reference honey of Apis mellifera. The two bottles on the right are genuine $M$. fuscopilosa (isabitto) and T. clavipes (ajavitte) honeys. On the left side the two labeled angelita (name given to Tetragonisca angustula) false honeys, putatively originated from purple and yellow blooming. In the middle is the A. mellifera honey extracted from combs.

Table 1. Description of honey samples.

\begin{tabular}{|c|c|c|c|c|}
\hline No. & 3-digit & Local name & $\begin{array}{l}\text { Entomological } \\
\text { identification }\end{array}$ & Origin \\
\hline 1 & 408 & $\begin{array}{c}\text { Angelita } \\
\text { (dark honey) }\end{array}$ & $\begin{array}{l}\text { False honey } \\
\text { (not bee made) }\end{array}$ & $\begin{array}{c}\text { Town market } \\
\text { Puerto Ayacucho }\end{array}$ \\
\hline 2 & 335 & $\begin{array}{c}\text { Angelita } \\
\text { (light honey) }\end{array}$ & $\begin{array}{l}\text { False honey } \\
\text { (not bee made) }\end{array}$ & $\begin{array}{c}\text { Town market } \\
\text { Puerto Ayacucho }\end{array}$ \\
\hline 3 & 120 & Abeja & Apis mellifera & Nature shop \\
\hline 4 & 510 & $\begin{array}{c}\text { Isabitto } \\
\text { (light honey) }\end{array}$ & $\begin{array}{c}\text { Melipona } \\
\text { fuscopilosa }\end{array}$ & $\begin{array}{l}\text { Paria Grande } \\
\text { forest }\end{array}$ \\
\hline 5 & 252 & $\begin{array}{c}\text { Ajavitte } \\
\text { (dark honey) }\end{array}$ & $\begin{array}{c}\text { Tetragona } \\
\text { clavipes }\end{array}$ & $\begin{array}{l}\text { Paria Grande } \\
\text { forest }\end{array}$ \\
\hline
\end{tabular}

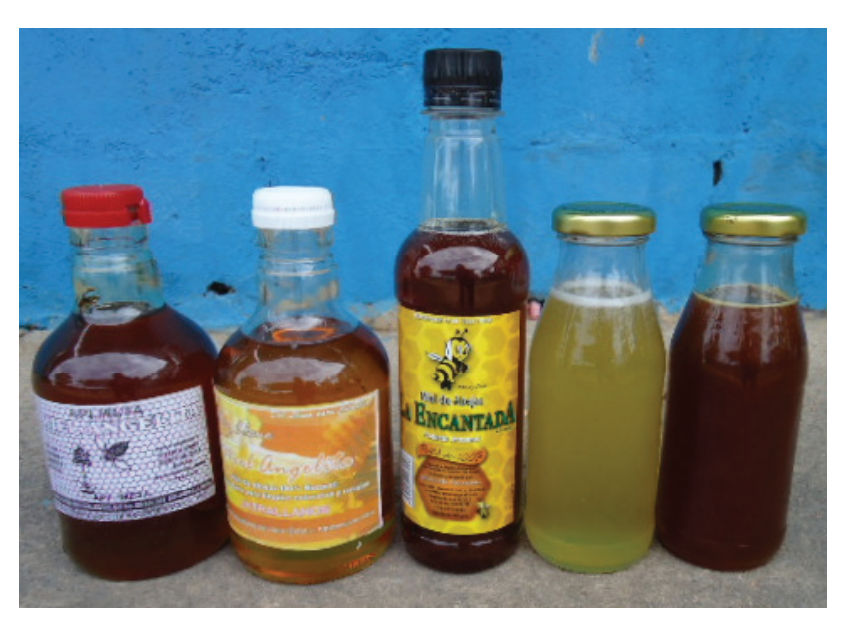

Figure 2. Stingless bee honeys from the Venezuelan Amazon, in Paria Grande. 


\section{Assessors}

A group of eight honey consumers, three females and five males, aged between 15 and 45 years old, from Paria Grande, a native Amerindian community took part in this study. They were selected based on their nutritional interest on honey, curiosity, commitment, availability and motivation. None of them had previous experience with sensory analysis, but all were familiar with forest pot honey. Their sense of smell was not altered by smoking, allergies, flues, or insomnia. The sessions took place in the morning, 2-3 $\mathrm{h}$ after breakfast. Their participation was voluntary and only rewarded with the pen they used to fill the forms. An informed consent form was filled prior to the sensory sessions.

\section{Sensory evaluation}

In the first session, assessors received a briefing of the FCP procedure and were instructed to provide a list of attributes to depict the honeys using their words to describe the appearance (color and visual consistency), odor, flavor (aroma and taste) and other sensations in their mouth and throat. Comparative and hedonic terms were avoided. About $5 \mathrm{~g}$ of each one of the five honeys showed in Table 1 were presented following a balanced presentation order, and participants were asked to list the sensory characteristics they perceived after tasting each honey. Honey samples were presented in capped plastic cups coded with three-digit numbers, in a daylight illuminated room. Appearance was evaluated first, then the odor, and finally half spoon of honey was tasted and any other sensation was also recorded. Mineral water was served to rinse the mouth between samples, as well as a piece of the local cassava cracker known as casabe, to reset the palate (Figure 3). For the second session, individual score cards were prepared to measure the intensities of each sensory attribute generated during the first session. The samples were evaluated monadically by using unstructured $10 \mathrm{~cm}$ line scales anchored with the words "weak" or "absent" at the left end, and "strong" at the right end. Each assessor crossed the intensity on the line scale in the position that best described his/her perception. Help was provided individually to facilitate the evaluation process without any induction.

\section{Statistical analysis}

The data acquired by FCP were analyzed by generalized Procrustes analysis, to generate an optimized consensus matrix by mathematical transformations, to reach a minimal overall deviation which was able to summarize the information about the samples, and replace the panel mean (Williams \& Langron, 1984). Correlations between the sample score of each sensory attribute and the corresponding sample score principal component, allowed the selection of the important attributes.

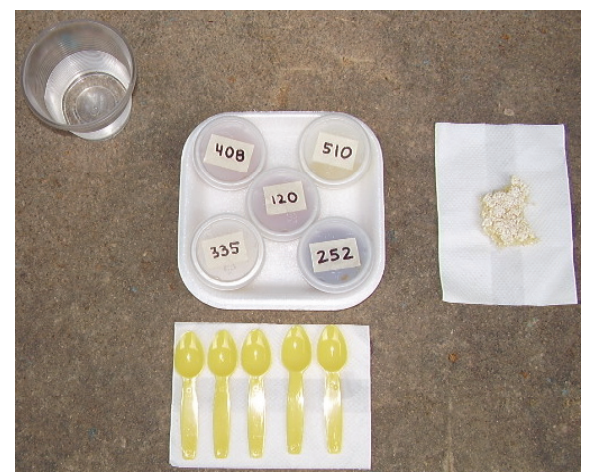

Figure 3. Presentation of honeys for sensory sessions.

\section{Results}

\section{Elicited sensory attributes}

The list of preliminary vocabulary elicited in the qualitative session was reduced to the 25 terms presented in Table 2, by the reduction of redundant and/or vague words. The eight assessors elicited on average thirteen sensory attributes (ranging from 10 to 16) for the five honey types produced by different species of Meliponini in different countries. For example fluid, thin, watery, viscous, thick etc. refer to low to high viscosity. The descriptor fermented was used to group alcohol, fermented and fermented pollen. Negative and positive correlations $(<-0.7$ and $>0.7)$ between each attribute and the first two dimensions are given for each one of the eight assessors. As suggested by Guàrdia et al (2010) only agreed descriptors with correlation coefficients higher than 0.6 in at least one of the first two dimensions were used to visualize the relationships between samples and attributes. The first dimension was better explained by low viscosity $(-0.8$ to $-1.0)$, fermented odor ( 0.9 to 1.0$)$ and sour taste ( 0.8 to 1.0$)$. However, brown color and the resin flavor also contributed to it. The second dimension coefficient's was more related to the fruity and honey odor, sweet, fresh fruit, fruity sweet and honey flavor. The sensation of biting nose was in the first dimension but burns the throat in the second. The assessors used many common words to describe the five honeys, but some sensory descriptors were unique and very specific, related to local resins named artocha, and fruits which are known as manteco.

As previously observed by Ferreira et al. (2009), the vocabulary developed to describe stingless bee honey by FCP, was similar to descriptors of appearance, odor, flavor, and trigeminal sensations used to describe $A$. mellifera honey by QDA (Vit 1993; Anupama et al. 2003; Persano Oddo \& Piro 2004; Galán-Soldevilla et al., 2005). 
This is a good evidence for the Codex Alimentarius Commission, to show that stingless bees also produce honey, as recognized by untrained panels using simple words to describe pot honey. However, besides the similarities, differences between honeys of each stingless bee species may be somehow comparable to the diversity attributed to botanical origins of the honey produced by only one bee species, the A. mellifera. Melipona species produce light amber honeys, while Trigona tends to produce dark amber honeys, similarly to the characteristic light amber acacia honey and dark amber chestnut honey, widely documented and familiar to beekeepers and consumers from locations where these honeys are produced. Besides that, the fermented descriptors are somehow distinctive in pot honey.

Assessors

Eight assessors elicited an average of 13 attributes (ranging from 10 to 16) of five honey types produced by different species of Meliponini in different countries. The attributes they provided are listed in Table 2 . The ability of each assessor seen from the combined attributes of all, is defined in the assessors' plot by principal components of the consensus configuration. Individual performance could be checked by looking at the graphic of residuals (Figure 4). The graphic of residuals for each assessor by configuration after the transformations along with the consensus plot for the five honey types shows that assessor 5 has the highest residual, which means that he gave rates that do not match the consensus.

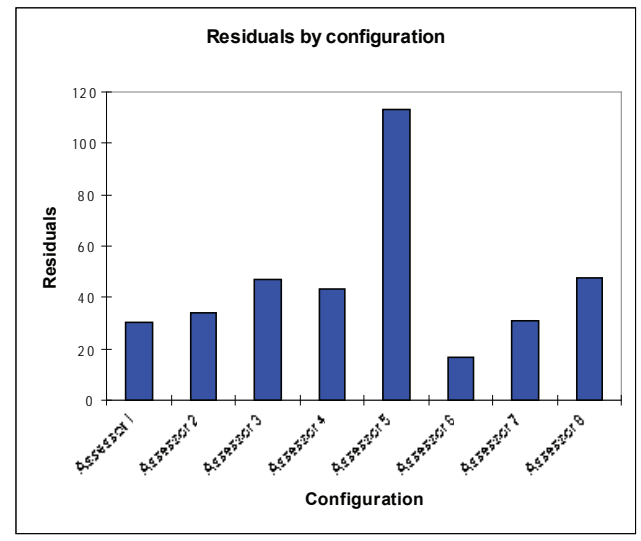

Figure 4. Residual variance for each assessor.

Honeys

Figure 5 shows the consensus configuration of the five honeys. In Figure 5a, the first dimension explained $39.50 \%$ of the variability and separated genuine pot honeys $(252,510)$ from the other samples. The honeys are widely spread in space. Genuine pot honeys M. fuscopilosa
(510) and T. clavipes (252) produced by the Paria Grande Piaroa community are grouped on the right, separated from the genunie $A$. mellifera (120) and the false honeys (335 and 408) grouped in the left by the first dimension, with conspicuous contributions of a low viscosity, fermented odor and sour flavor. On the other hand, the second dimension explained $24.69 \%$ of the variability, and separated sample 510 from the others. The genuine Melipona honey 510 is set apart from the rest in the upper position of the dimension 2, which was explained by fresh fruit, honey, and burns the throat descriptors (Figure 5b). Despite the light and dark color of false honey to imitate genuine pot honey, the artificial dark amber honey 408 is close to the other artifical honey (335) revealing similar sensory characteristics between them. The genuine dark Tetragona honey 252 was positioned separately in dimension 1 showing that it was perceived by participants with specific sensory attributes. The color imitation of angelita honey samples (Figure 2) was surpassed by the other sensory attributes that positioned the honeys in opposite compartments. Indeed, the sour taste and intrinsic flavor of the light false honey angelita was more similar to Apis honey.

Figure 6 shows the residuals by object after the transformations. We can see that the dark artificial honey 408 has the smallest residual. This indicates that there is most probably a consensus between assessors when evaluating this syrup honey. Whereas the highest residual is for the light artificial honey 335, which is a more elaborated syrup honey with sharper sour taste than traditional false honeys the author has been observing for more than twenty years in the Venezuelan market.

The Melipona honey is characterized by the honey in the nose and the mouth, fresh fruit flavor, honey odor and aroma, and the sensation of burning the throat. The Tetragona honey is more complex, and was described as having brown color, sour and bitter taste, fermented flavor, peanuts, resin, biting nose. The Apis honey was perceived as having the caramel aroma, honey, sweet taste and medicinal aroma. The higher viscosity was attributed to the false honeys, the angelita dark amber had an odorless attribute, while the other angelita light amber was more elaborated medicinal, caramel and sweet.

Figure 7 presents the consensus configuration showing the investigated honey sensory attributes. False honeys are closer to the A. mellifera honey, and not distinctive putative yellow and purple blooming was separated from both of them, so only one group of false honey. Pot honeys were spread in distinctive positions by the two first dimensions. The Melipona honey was characterized by sour taste, fresh fruit, honey and burns the throat attributes, while the Tetragona had more descriptors such as brown color, bitter and sour taste, fermented, fruity, resin, biting nose. 
How a Huottuja (Piaroa) community perceives genuine and false honey from the Venezuelan Amazon, by free-choice profile sensory method
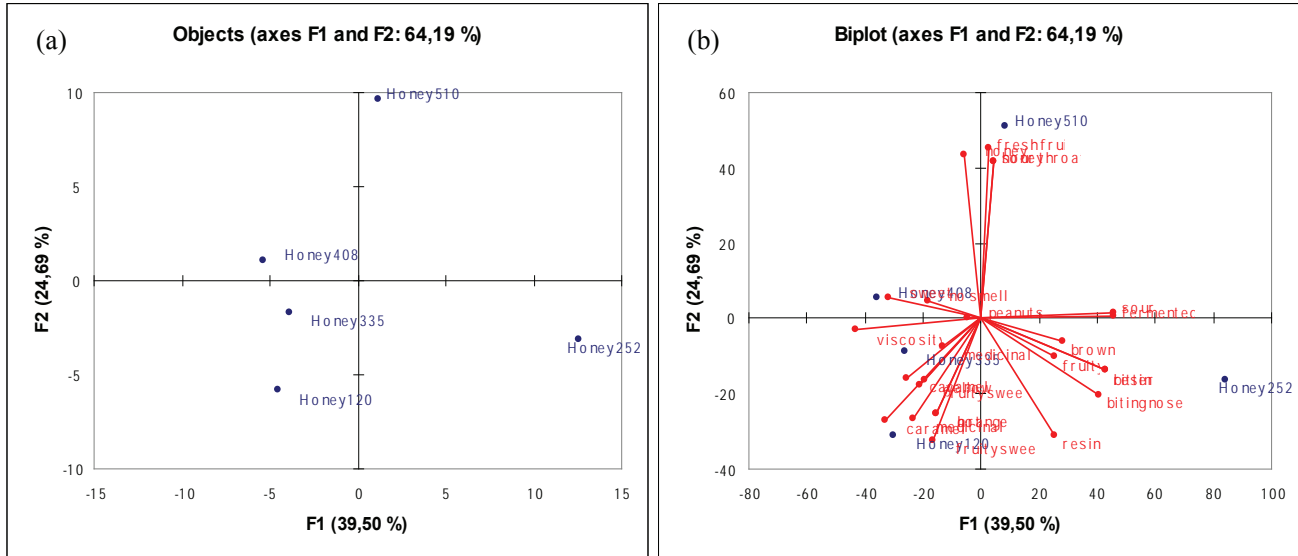

Figure 5. The five honeys, defined by the first two dimensions of the consensus configuration, showing (a) Position of honey samples, (b) Sensory attributes. See Table 1 for the identification of honey samples.

Table 2. Attributes better correlated with the first two dimensions (D1, D2), and attributes of honeys.

\begin{tabular}{|c|c|c|c|c|c|c|c|c|c|c|c|c|c|c|c|c|}
\hline \multirow{2}{*}{$\begin{array}{l}\text { Assessors } \\
\text { Dimensions }\end{array}$} & \multicolumn{2}{|c|}{1} & \multicolumn{2}{|c|}{2} & \multicolumn{2}{|c|}{3} & \multicolumn{2}{|c|}{4} & \multicolumn{2}{|c|}{5} & \multicolumn{2}{|c|}{6} & \multicolumn{2}{|c|}{7} & \multicolumn{2}{|c|}{8} \\
\hline & D1 & D2 & D1 & D2 & D1 & D2 & D1 & D2 & D1 & D2 & D1 & D2 & D1 & D2 & D1 & D2 \\
\hline \multicolumn{17}{|l|}{ ATTRIBUTES } \\
\hline \multicolumn{17}{|l|}{ Appearance } \\
\hline 1. yellow color & & & & & & & -0.8 & & & -0.7 & & & & & & \\
\hline \multicolumn{17}{|l|}{ 2. orange color } \\
\hline 3. brown color & & 0.7 & 0.7 & & & & 1.0 & & & 0.7 & & & & & & \\
\hline 4. viscosity & -0.9 & & -1.0 & & -0.9 & & -0.9 & & -0.9 & & -0.9 & & -0.8 & & -1.0 & \\
\hline \multicolumn{17}{|l|}{ Odor } \\
\hline 5. fermented & 1.0 & & & 0.9 & 0.9 & & 0.9 & & & & 0.9 & & 0.9 & & & 0.9 \\
\hline 6. fruity & & 0.9 & & & & & 0.8 & & & & & & & -0.7 & & \\
\hline 7. fruity sweet & & & & & & & & & & & 0.9 & & & & & \\
\hline \multicolumn{17}{|l|}{ 8. caramel } \\
\hline \multicolumn{17}{|l|}{ 9. peanuts } \\
\hline 10. honey & & & & & & & & & & & & 0.9 & & 0.9 & & \\
\hline 11. resin & & -0.7 & & & & & & & & & & & & & & \\
\hline \multicolumn{17}{|l|}{ 12. medicinal } \\
\hline \multicolumn{17}{|l|}{ 13. odorless } \\
\hline \multicolumn{17}{|l|}{ Flavor } \\
\hline 14. sweet & -1.0 & & & 0.8 & & & & & & & & & & & & 0.9 \\
\hline 15. sour & 1.0 & & 0.9 & & & & 1.0 & & 0.8 & & 1.0 & & & & 1.0 & \\
\hline 16. bitter & & & & & & & & & & & & & & & 0.9 & \\
\hline \multicolumn{17}{|l|}{ Aroma } \\
\hline \multicolumn{17}{|l|}{ 17. hot } \\
\hline \multicolumn{17}{|l|}{ 18. candy } \\
\hline 19. fresh fruit & & & & 0.9 & & 0.9 & & & & & & & & & & 0.9 \\
\hline 20 . fruity sweet & & & & -0.7 & & & & & & & & & & & & -0.7 \\
\hline \multicolumn{17}{|l|}{ 21. medicinal } \\
\hline 22. resin & 0.9 & & 0.9 & & & & & & & & & & & & 0.9 & \\
\hline 23. honey & & & & & & & & & & & & 0.9 & & 0.9 & & 0.9 \\
\hline \multicolumn{17}{|l|}{ Trigeminal sensations } \\
\hline 24. biting nose & 0.9 & & & -0.7 & & & & & & & & & & & 0.9 & \\
\hline 25. burns the throat & & 0.9 & & & & & & & & & & & & & & \\
\hline
\end{tabular}




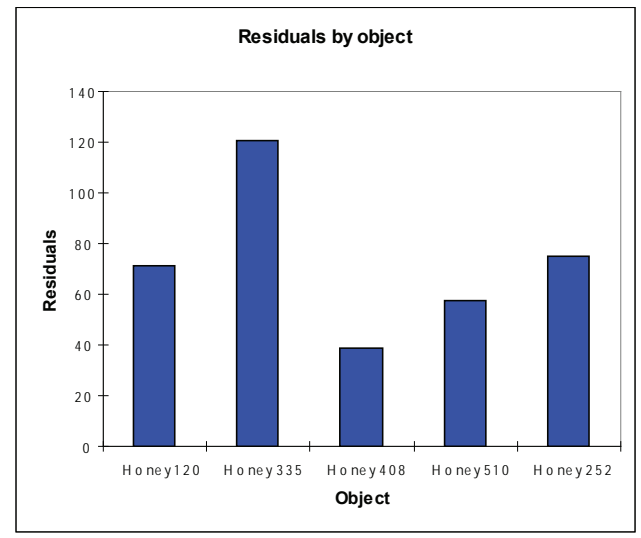

Figure 6. Residual variance for each honey.

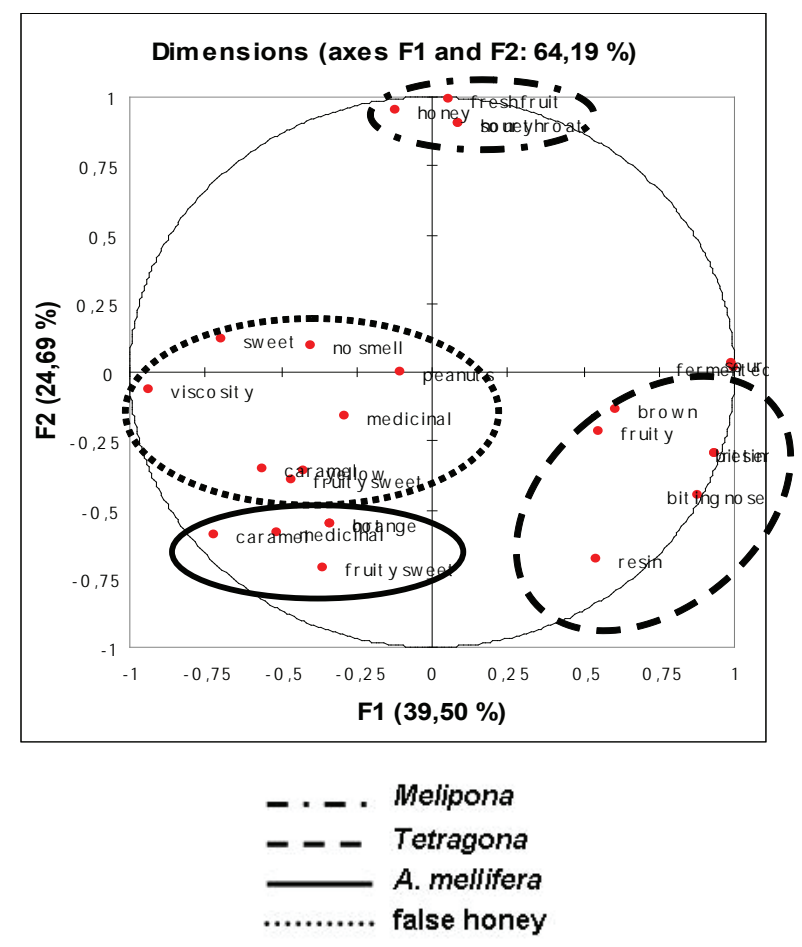

Figure 7. Distribution of the honey attributes along the two first dimensions.

\section{Discussion}

The separation of the bee genera observed in Figure 5 was also obtained by multivariate analysis of physicochemical factors in Venezuelan pot honeys (Vit et al. 1998). However, in this work $A$. mellifera and artificial honeys were incorporated, and the information derived from the FCP was promising for self control of honey authenticity by the Huottuja community. This experience could be wisely extended in schools, so children would learn how to discriminate a honey that is not genuine, from their traditional forest honeys, that are now produced in rational hives. The better knowledge of their products could protect them with arguments of valorization.

The first dimension was better explained by low viscosity $(-0.8$ to -1.0$)$, fermented odor $(0.9$ to 1.0$)$ and sour taste ( 0.8 to 1.0$)$, also brown color and the resin flavor contributed to it. The second dimension was more related to the fruity and honey odor, sweet, fresh fruit, fruity sweet and honey flavor. The sensation of biting nose was in the first dimension but burns the throat in the second.

Compared to the genus of Apis, which has eleven species, stingless bees have some sixty genera, and are the only group of social bees with a Cenozoic fossil record (Rasmussen \& Cameron, 2010). Therefore, more variability is expected for the pot honey they produce due to the differences attributed to their entomological origin, additionally to the botanical and geographical origin.

Local names of stingless bees in the Huottuja language, such as "isabitto" (Melipona fuscopilosa) and "ajavitte" (Tetragona clavipes) are unfamiliar to Spanish speakers. Melipona species have common names such as "erica" and "guanota, while Tetragonisca angustula is known as "angelita" (Vit et al., 2004). In the honey label, the name of the bee in the tropics could become as important as the name of the botanical source of unifloral honeys in Europe. However, local names of stingless bees in Venezuela have been more used in labels of artificial or false honey, than in the traditional industry of meliponiculture, due to several constraints, - especially the lack of official standards for Meliponini honey, and also the fact that this is a rural practice not organized in cooperatives, which are essential to handle the marketing.

A better sensory knowledge of the forest honey harvested by the Huottuja people followed by the available information would aggregate monetary value to the product, and could contribute to the improvement of the community life conditions. Their cultural values would benefit by assessing the environmental and social roles of meliponiculture, but the suggested price-based and quantity-based techniques of valuation for indigenous cultural heritage, need further economical analysis to improve social welfare concepts (Venn \& Quiggin, 2007). Pot honey hunting has been reported for bush honey or sugarbag used by Gunwinggu community (Trigona species named "bobitj" and "man.gung") in Australia (Altman, 1984).

In conclusion, this is the first time a Huottuja community has carried out a honey tasting of the traditional pot honey available in their forest and recently harvested from their stingless bee apiaries. The classic approach of Free-choice profile was successfully handled by the local people of the community area, with the honey we needed to test. Huottuja assessors were interested in the contribution they were giving, and their sensory skills were adequate to accomplish the differentiation of the honey types, as confirmed by the routine statistical test. A more knowledgeable consumer improves the protection 
of customers against false honey. Sensory approaches like ours confirm the useful value of sensory evaluation to differentiate diverse entomological origins of honey.

\section{Acknowledgement}

The authors thank Mr. Fini Opa Carrasquel, who provided the genuine pot honey to carry on sensory analysis. To the late meliponine entomologists JMF Camargo, from the Departamento de Biologia, Faculdade de Filosofia, Ciências e Letras de Ribeirão Preto, Universidade de São Paulo, Ribeirão Preto, SP, Brazil, for the valuable identification of stingless bees. To CDCHT-ULA project FA-458-09-03-B.

\section{References}

Altman JC 1984. The dietary utilisation on flora and fauna by contemporary hunter-gatherers at Momega Outstation, north-central Arnhem Land. AAS 1:35-46.

Anupama D, Bhat KK, Sapna VK 2003. Sensory and physicochemical properties of commercial samples of honey. Food Res Int 36: 183-191.

Camargo JMF, Pedro SRM 2007. Meliponini Lepeletier, 1836. In: Moure JS, Urban D, Melo GAR (org.). Catalogue of bees (Hymenoptera, Apoidea) in the Neotropical region. Curitiba: Sociedade Brasileira de Entomologia, p. 272578.

Codex Alimentarius Commission 1969. CAC/RS 12-1969. Norma Regional Europea para Miel. Roma: Programa Conjunto FAO/OMS; 29 pp.

Codex Alimentarius Commission 1987. CODEX STAN 12-1981. Revised Codex Standard for Honey; 17 pp.

Codex Alimentarius Commission 2001. CODEX STAN 12-1981. Revised Codex Standard for Honey; 7 pp.

Covenin 1984. Miel de Abejas. Comisión Venezolana de Normas Industriales COVENIN 2194-84. Fondonorma; Caracas, Venezuela; 5 pp.

Ferreira EL, Lencioni C, Benassi MT, Barth MO, Bastos DHM 2009. Descriptive sensory analysis and acceptance of stingless bee honey. Food Sci Tech Int 15: 251-258.

Kerr WE 1987. Abelhas indígenas brasileiras (meliponíneos) na polinização e na produção de mel, pólen, geoprópolis e cera. Informe Agropecuario 13: 15-22.

Kidder DP, Fletcher JC 1857. Brazil and the Brazilians, portrayed in historical and descriptive sketches, Philadelphia and New York pp.454-455, apud Bull Am Mus Nat Hist 90: 1-546, 1948.

Galán-Soldevilla H, Ruíz-Pérez-Cacho MP, Serrano Jiménez S, Jodral Villarejo M, Bentabol Manzanarez A 2005. Development of a prliminary sensory lexicon for floral honeys. Food Qual Pref 16: 71-77.

Guàrdia MD, Ana PS, Aguiar APS, Claret A, Arnau J Guerrero L 2010. Sensory characterization of dry-cured ham using free-choice profiling. Food Qual Pref 21: 148-155.

Gonnet M, Lavie P, Nogueira-Neto P 1964. Étude de quelques characteristiques des miels récoltés para certains
Méliponines brésiliens. Comptes Rendus Acad Sci Paris 258: 3107-3109.

Melnyk M, Bell N 1996. The direct-use values of tropical moist forest foods: The Huottuja (Piaroa) Amerindians of Venezuela. Ambio 25: 469-472.

Michener CD 2000. The Bees of the World. Baltimore: The Johns Hopkins University Press.

Ministério da Agricultura 2000. Regulamento Técnico de Identidade e Qualidade do Mel. Instrução Normativa. http://extranet.agricultura.gov.br/sislegis-consulta/ servlet/VisualizarAnexo?id=1690, accessed in August 2006.

Norma Técnica Colombiana 2007. Miel de Abejas. NTC 1273. Instituto Colombiano de Normas Técnicas y Certificación, Bogotá, http://www.sinab.unal.edu.co/ntc/NTC 1273. pdf, accessed in June 2010.

Persano Oddo L, Piro R 2004. Main European unifloral honeys: descriptive sheets. Apidologie 35: S38-S81.

Rasmussen C, Cameron SA 2010. Global stingless bee phylogeny supports ancient divergence, vicariance, and long distance dispersal. Biol J Linn Soc 99: 206-232.

Schwarz HF 1948. Stingless bees (Meliponidae) of the western hemisphere. Bull Am Mus Nat Hist 90: 1-546.

Souza BA, Roubik DW, Barth OM, Heard T, Enríquez E, Carvalho CAL, Marchini LC, Villas-Bôas J, Locatelli JC, Persano Oddo L, Almeida-Muradian L, Bogdanov S, Vit P. Composition of stingless bee honey: Setting quality standards. Interciencia 31: 867-875.

Venn TJ, Quiggin 2007. Accomodating indigenous cultural heritage values in resource assessment: Cape York Peninsula and the Murray-Darling Basin, Australia. Ecol Econ 61: 334-344.

Vit P 1993. Miel de Abejas. Mérida: Consejo de Publicaciones Universidad de Los Andes.

Vit P, Medina M, Enriquez ME 2004. Quality standards for medicinal uses of Meliponinae honey in Guatemala, Mexico and Venezuela. Bee World 85: 2-5.

Villas-Bôas JK 2008. Meliponicultura e povos indígenas no Brasil. In: Vit P (ed). Abejas sin aguijón y valorización sensorial de su miel. Mérida, Venezuela: APIBAFacultad de Farmacia y Bioanálisis, DIGECEX, Universidade de Los Andes, p. 31-33.

Vit P, Persano Oddo L, Marano ML, Salas de Mejías E 1998. Venezuelan stingless bee honeys characterised by multivariate analysis of compositional factors. Apidologie 29: 377-389.

Williams AA, Langron SP 1984. The use of free choice profiling for evaluation of commercial ports. J Sci Food Agric 35: 558-568.

\section{*Correspondence}

Patricia Vit

Departamento Ciencia de Los Alimentos, Facultad de Farmacia y Bioanálisis, Universidad de Los Andes, Mérida 5101, Venezuela vit@ula.ve

Tel +582742403565

Fax: +58 2742403475 